1991 Accelerator Instrumentaiion Worksiop, Newport News, VA, October 28-31, 1991.

\title{
BEAM INSTRUMENTATION IN THE AGS BOOSTER*
}

\author{
R. L. Witkover \\ AGS Department, Brookhaven National Laboratory \\ Upton, NY, 11973
}

\section{Abstract}

The AGS Booster was designed to accelerate low intensity $\left(2 \times 10^{10}\right)$ polarized protons, high intensity $\left(1.5 \times 10^{1-}\right)$ protons and heavy ions through $\mathrm{Au}+33$. Coping with this wide range of beams, the $3 \times 10^{-11}$ Torr vacuum and the radificion environment presented challenges for the beam monitors. Some of the more interesting instrumentation design and performance during the recent Booster proton commissioning will be described.

\section{Description of the Booster}

The AGS Bonster will: (1) Increase AGS proton intensity $b_{l}$ injecting 4 Booster pulses per AGS cycle at $1.5 \mathrm{GeV}$ versus $200 \mathrm{MeV}$. (2) Raise AGS polarized proton intensity by accumulating 20 Linac pulses each AGS cycle. (3) Accelerate ions through $\mathrm{Au}^{+3} 3$ to AGS injection energy for further acceleration and transfer to RHIC. Figure 1 shows the Booster layout. The $201.8 \mathrm{~m}$ circumference has 48 half-cells with 6 missing dipoles. The flexible magnet supply typically follows one of three cycles during an AGS cycle: 4 pulses at $7.5 \mathrm{~Hz}$ for protons, a 2.667 sec injection porch with $0.133 \mathrm{sec}$ up-down ramp for polarized proton accumulation and a 1.4 - 2 sec ramp for heavy ions. These can be incerleaved freely and special study cycles added within these. The $\mathrm{RF}$ duration ranges from $60 \mathrm{msec}$ for protons (2.5 - 4.1 $\mathrm{MHz})$ to 620 , nec for $\mathrm{Au}^{+33}(0.852-3.06 \mathrm{MHz})$. Protons are acceleraced on the 3 rd harmonic but ions will begin on the 12 th and switch to the $3 \mathrm{rd}$. Protons from the Linac are chopped at the Booster RF frequency with the width varied during injection to optimally paint the bucket. There will be four bucket-to-bucket transfers to the AGs for high intensity protons, but be only 1 for heavy ions or polarized protons.

Booster beam intensity is measured using a fast current transformer for injection and capture, with a lower frequency transformer for the remainder of the cycle. Bunch longitudinal density is observed using wall

*Work performed under the auspices of the U.S. Department of Energy.

DISTRIBUTION OF THIS DOCUMENT IS UNNLLIVIITEO

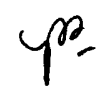


current monitors. Beam loss is monitored in each halfcell by a 4-m long coaxial ion chamber described in the last Instrumentation Workshop. 1 An IPM (ionization profile monitor) is used to measure beam profile. It uses two layers of micro-channel plates ${ }^{2}$ to increase the signal in the $10^{-1 .}$ Torr vacuum. It is described in detail in another paper at this Workshop.

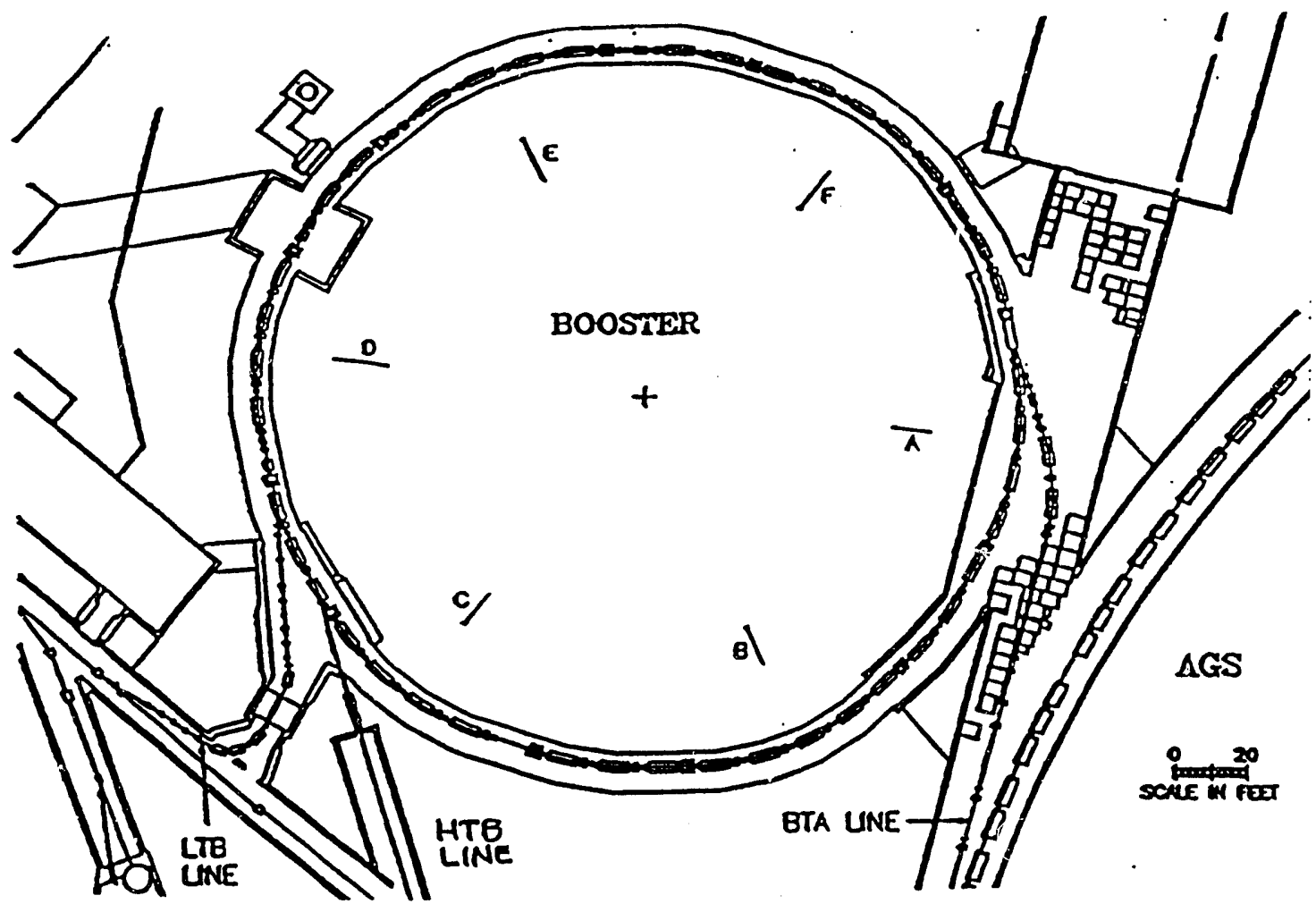

Fig. 1. Layout of the Booster and its transport lines.

High intensity and polarized $\mathrm{H}^{-}$beams are injected via the LTB line, a branch off the line to the AGS. HARP multiwire profile monitors ${ }^{3}$ located upstream of the $126^{\circ}$ bend and just before the Booster are used to measure emittance. Beam current is measured at the ends of the LTB line by conventional beam transformers with 10 and $100 \mu \mathrm{A} / \mathrm{V}$ and $10 \mathrm{~mA} / \mathrm{V}$ ranges, $70 \mathrm{nsec}$ risetime (low gain) and $1 \% / \mathrm{msec}$ droop. Eight $4-\mathrm{m}$ long coaxial ion chambers measure radiation and stop the Linac beam for high losses. Stripline couplers 4 with wideband electronics measure beam position at 7 locations.

Ion beams from $\mathrm{H}^{+}$to $\mathrm{Au}^{+33}$ are transported from the Tandem Van de Graaff to Booster in the HTE line, an extension of HITL. 5 Eight HARPs and 3 beam current transformers of the type used in LTB and HITL monitor the beam. Faraday cups at each HARP location measure 
current from $1 \mu \mathrm{A}$ to several hundred $\mu \mathrm{A}$ in the pulsed beam down to the nano-Amp $D C$ beam used for tuning HTB. This line now being commissioned.

Beam is extracted to the AGS in the BTA Iine. HARPs provide profile data at 4 locations. Total charge in the 3 bunches is measured at 3 locations in the BTA line by wideband current transformers with fast integrator electronics. Position is monitored at 6 locations using the same puEs as in the Booster Ring. Eight fixed location $7-\mathrm{m}$ long coaxial loss monitors measure beam loss aided by 8 relocatable detectors.

\section{The Design Problems}

Most of the instrumentation was designed to operate from $<2 \times 10^{10}$ to $>1.5 \times 10^{13}$ charges per cycle with 2 decades of resolution. Some electronics had to be in the tunnel to provide the bandwidth and low noise required, exposing them to radiation from high intensity protons which can be inter-leaved with low intensity beams. For 4800 hours of proton operation (an over estimate) the typical dose at floor level was estimated 6 to be $5.4 \mathrm{kRad}$ and $3.4 \times 10^{12} \mathrm{n} / \mathrm{cm}^{2}$. The fiber optic links used for the Ring PUE signals were tested in the AGS to over $50 \mathrm{kRad}$, similar to 5 years in the Booster. At hot locations, such as the interilal beam dump, shielding is required. High dose radiation monitors (TLDs) were placed with the electronics to provide data for failure analysis. Higher radiation at beam height precludes materials such as PTFE for cables or connectors. Since PTFE is used in most high temperature cables, bakeout of the Ring vacuum system at $300^{\circ} \mathrm{C}$ presented problems. The $3 \times 10^{-11}$ Torr Ring vacuum requirement limited retector materials to ceramic and stainless steel. The PUEs had to retain tight tolerances even after vacuum firing at $950^{\circ} \mathrm{C}$. Some of the solutions to these challenges will be described.

\section{The Loss Monitor System}

An array of 64 fixed-position and 16 relocatable coaxial ion chambers measure beam loss. The detectors are made from 7/8-inch diameter air dielectric coaxial cable (Andrew type HJ5-50), closed at the ends and pressurized with Argon to 10 PSIG. A $200 \mathrm{~V}$ DC bias is applied to the center conductor of each detector by its own floating DC-to-DC converter, allowing a single signal coax for both bias and signal and response cown to DC. The output from each detector is integrated by a low leakage circuit $(<10 \mathrm{pA})$, digitized and put into 
dual ported memory at a $140 \mathrm{kilo-word} \mathrm{rate} \mathrm{by} \mathrm{a} \mathrm{scanning}$ ADC. The system is fully described in Reference 1.

The loss monitors were an important tool in the Booster commissioning. Typical current in the LTB line was $25 \mathrm{~mA}$, but losses from a $1.5 \mathrm{~mA}, 25 \mu \mathrm{sec}$ beam were easily seen. Most of the Ring commissioning used only a single injected turn $(1.2 \mu \mathrm{sec})$ for a nominal intensity of $2 \times 1010$ protons, the lower design limit. offset and noise in the high gain state was typically 10 counts of a maximum of 2047 . Figure 2 shows the integrator output for an interesting loss in LTB. The rapid (1-2 $\mu \mathrm{sec})$ rise at the edges of the pulse were explained when the LTB BPMs showed large position excursions at the same time (Figure 3). These are believed to be beam swept by the chopper which survived the Linac and HEBT. The pulse-to-pulse losses were displayed as a bar graph in which any 25 selected units or groups can be displayed.

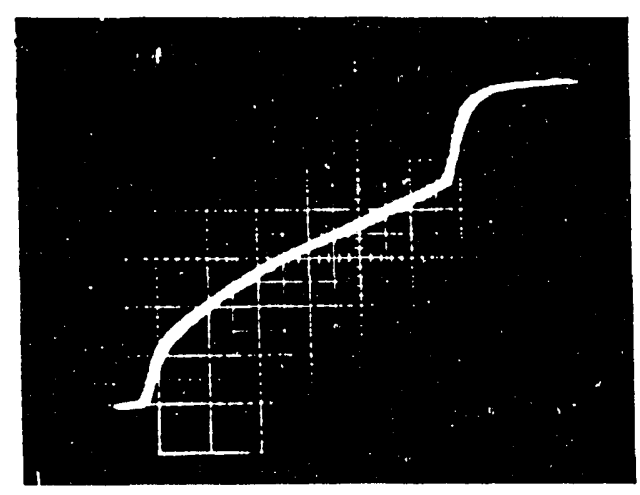

Fig. 2. Integrated LTB Beam Loss Monitor Output. $200 \mathrm{mv} / \mathrm{Div}$., $5 \mu \mathrm{sec} / \mathrm{Div}$.

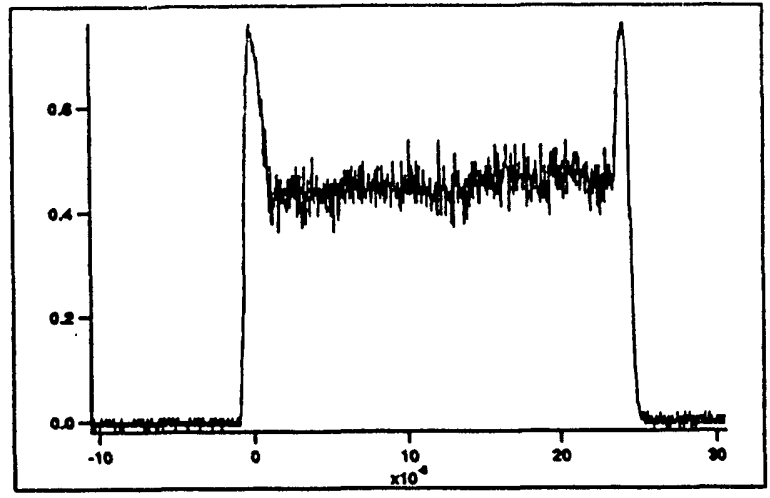

Fig. 3. Corresponding LTB Beam Position Monitor output. Y-axis in $\mathrm{mm}$, $\mathrm{X}$-axis in $\mu \mathrm{sec}$.

\section{Ring beam Current Transformers}

Beam current in the Ring can be less than $100 \mu \mathrm{A}$ at injection to $2.9 \mathrm{~A}$ at full intensity. To meet the time response requirement of $<1 \mu \mathrm{sec}$ to observe stacking, to almost 3 sec for accumulating polarized beam, an injection beam monitor (BIBM) and a separate circulating beam monitor ( $B C B M)$ were installed, each covering the full intensity range.

The BIBM is a conventional beam current toroid 7 with a sensitivity of $0.1 \mathrm{~V} / \mathrm{A}$ into 50 ohms and bandwidth from $2 \mathrm{~Hz}$ to $8 \mathrm{MHz}$, enclosed in a $170 \mathrm{~mm}$ ID aluminum case. The electronics, located at floor level, are 
similar to those in LTB and HTB, but with gains of 1 $\mathrm{mA} / \mathrm{V}, 10 \mathrm{~mA} / \mathrm{V}$ and $1 \mathrm{~A} / \mathrm{V}$. The rise time is $70 \mathrm{nsec}$ for the high and $1 \mu$ sec for the low intensity range.

The BCBM is a current transformer (DCCT) employing magnetic modulation at $6.928 \mathrm{kHz}$ with synchronous 2nd harmonic detection 8 to provide DC to $15 \mathrm{kHz}$ bandwidth. This commercial unit 9 uses specially annealed metal glass tape cores. The BCBM is $170 \mathrm{~mm}$ ID and $62 \mathrm{~mm}$ long including magnetic shielding. The Front End Electronics (FEE) must be within $3 \mathrm{~m}$ of the detector but the Back End Electronics (BEE) can be up to $300 \mathrm{~m}$ away. The standard ranges of $1 \mathrm{~A} / \mathrm{V}$ and $10 \mathrm{~mA} / \mathrm{V}$ produced only $1 \mathrm{mV}$ for a $10 \mu \mathrm{A}$ beam, so a relay switched gain of 10 amplifier was added after the FEE. DCCTs claim $1 \mu \mathrm{A}$ resolution when viewed with a 1 sec integration window during which modulation, Barkhausen and environmental noise average out. This is applicable for storage ring beams but not for pulsed beams. Two of 3 samples showed modulation noise equivalent to $\pm 150 \mu \mathrm{A}$, consisting of spikes and components at the fundamental and odd harmonics. A filter with $-40 \mathrm{~dB}$ notches at 6.928 and 20.782 $\mathrm{kHz}$ reduced this to $\pm 10 \mu \mathrm{A}$ of 5 th harmonic. This was removed by a 4 th order $21 \mathrm{kHz}$ Butterworth low pass leaving about $10 \mu \mathrm{A}$ pp random noise. The third unit showed much less initial noise and required only the low pass filter.

The two transformers are housed in a $1.27 \mathrm{~cm}$ thick 1006 steel magnetic shield mounted on vibration isolators. A water cooled copper sheet keeps the detector temperature under $80^{\circ} \mathrm{C}$ during $300^{\circ} \mathrm{C}$ bakeout. A ceramic vacuum pipe section forces the wall current to a lower impedance path outside the transformers. The FEE and BIBM circuits are located near the floor in a steel electrical box with steel conduit shielding the cables to the detectors. An injection kicker, which is pulsed to $500 \mathrm{~A}$, located $30 \mathrm{~cm}$ away, produced about $100 \mathrm{\mu A}$ pickup on the BCBM and somewhat more on the BIBM. Additional shielding will be provided. No RF pickup was observed up to $3.5 \times 10^{12}$ but similar units in the AGS showed some above $5 \times 10^{12}$. Figure 4 shows the BCBM output for a single turn of injected beam with $1.65 \mathrm{x}$ $10^{10}$ protons accelerated to $1.2 \mathrm{GeV}$ then decelerated down to $200 \mathrm{MeV}$. The lower trace is the same signal "normalized" to remove the velocity dependence.

\section{LTB Beam Position Monitors}

The 7 dual plane stripline BPMs the LTB line were designed for use with the high intensity $\mathrm{H}^{-}$beam, but may be extended for polarized beam by redesigning and 

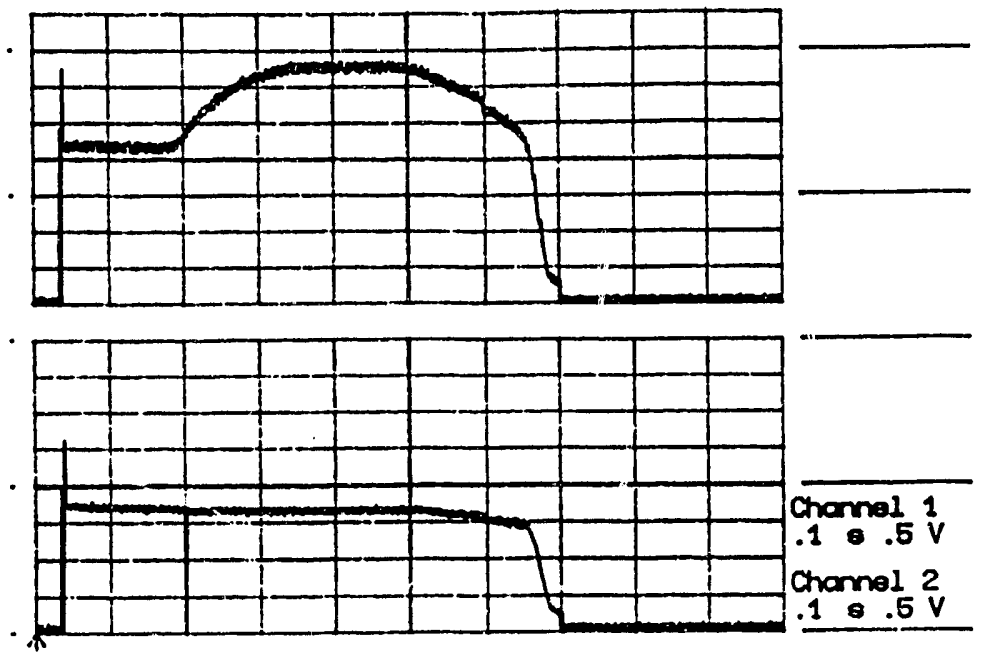

Fig. 4. Channel 1: raw BCBM output during Booster acceleration and deceleration. $0.5 \mathrm{~mA} / \mathrm{Div} ., 0.1$ sec/Div.; Channel 2: same normalized to give charge. $5 \times 10^{9} /$ Div., 0.1 sec/Div.

resonating the striplines 10 and adding input preamplifiers. The $\mathrm{H}$ and $\mathrm{V}$ planes were displaced longitudinally to reduce coupling, which can be important if the strips are resonated. To save space the detectors were designed for twice the RF frequency, $402.5 \mathrm{MHz}$, cutting the length almost in half with a loss of only $5 \%$ in amplitude. This also moved the frequency away from the Linac RF, reducing the background noise.

The signals are AM/PM processed 11 directly at 402.5 MHz without down conversion.12 This increased the bandwidth but made the limiter stage which remove the amplitude dependence of the phase modulated signal very difficult. By selecting the Plessey 532C limiters in pairs matched better than $0.18^{\circ}$, the 4 stage limiter provides $\pm 0.5 \mathrm{~mm}$ precision over a 26 dB dynamic range as measured with beam. The position bandwidth was found to be $10 \mathrm{MHz}$ in bench tests. During early Booster commissioning the BPMs appeared to give reasonable results with the beam nearly centered in the LTB line. Figure 3 shows the horizontal position after the big bend in LTB with the "horns" described above. Later in the commissioning, when the beam was run $20-30 \mathrm{~mm}$ off center to optimize Booster injection, the computed position appeared to saturate. Position calculated from scope traces did not show the apparent saturation. Later tests indicated that while small errors in calibration 
did exist, the primary cause was probable mis-timing of the data acquisition.

\section{Booster Ring Beam Position Monitors}

Ring beam position is measured using split plate, capacitive pick up electrodes (PUEs) 13 to provide low frequency response for the heavy ion bunches. Measurements have shown the linearity to be $< \pm 0.1 \mathrm{~mm}$ over \pm 30 $\mathrm{mm}$ of the $15 \mathrm{~mm}$ radius. 3.4 A $20-\mathrm{cm}$ long single plane PUE is located at the quadrupole (beta-max) in almost every half-cell and at six places in the BTA line to the AGS. The single turn trajectory or the average orbit can be acquired by varying the number of bunches integrated. The electronics are separated from the PUE by 10 feet of cable to maximize the voltage, minimize the noise and extend the low frequency response. All timing, commands, digital data and analog signals are carried over fiber optic links to prevent ground loops. Data can be read from all pUEs every $10 \mathrm{msec}$.

To meet the vacuum specification the complete assembly had to be vacuum fired at $950^{\circ} \mathrm{C}$ but maintain the mechanical stability to within $\pm 0.1 \mathrm{~mm}$ of the original, as confirmed by measurements. The resulting double gimbal support (Figure 5) also provided a means of

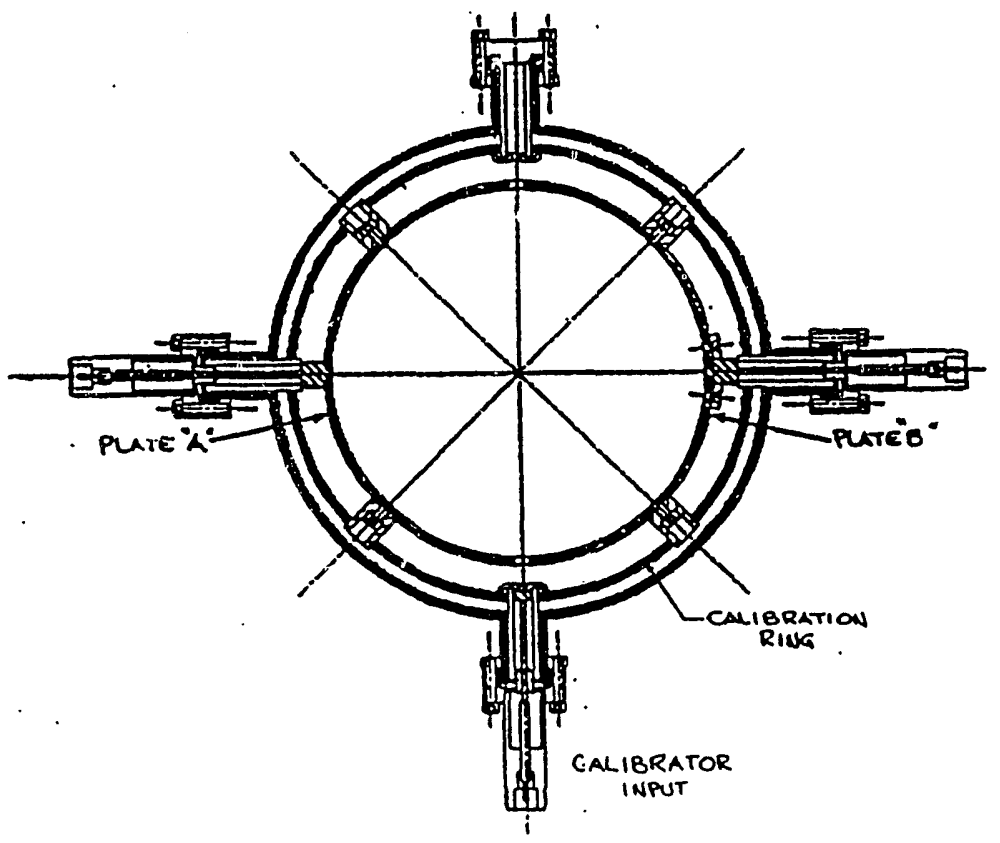

Fig. 5. Booster PUE showing double Gimbal support. 
coupling calibration signals to the electrodes. The $316 \mathrm{~N}$ stainless steel cylindrical tlectrodes are locked together at two end points with ceramic posts. Four radial ceramic posts fastened to the plates pass through close-fit holes in the calibration ring surrounding the electrodes. Four additional holes, closely fitted to ceramic sleeves on the vacuum feedthroughs, support the calibration ring from the vacuum shell. The electrodes are free to expand and contract axially while sliding radially along the ceramic posts.

Cables to withstand the $300^{\circ} \mathrm{C}$ bakeout are usually made of PTFE, which would soon fail in the expected radiation. A thermal isolator was designed which dropped the temperature to $60^{\circ} \mathrm{C}$ allowing standard polyethylene RG-62 cable to be used. The isolator consisted of a $15 \mathrm{~cm}$ stainless steel type-N adapter with a stainless inner conductor supported by ceramic disks. For additional RF shielding the cable was run in copper tubing.

The electronics cover 3 decades of intensity with resolution of $\pm 0.1 \mathrm{~mm}$. They were designed for bunch lengths from 3750 to $50 \mathrm{nsec}$ as the RF went from 0.21 4.1 $\mathrm{MHz}$ using $3 \mathrm{rd} \mathrm{h.rmonic} \mathrm{acceleration.} \mathrm{Now} \mathrm{heavy} \mathrm{ions}$ will start on the 12th harmonic (0.84 $\mathrm{MHz} R F)$ and later switch to the 3rd. A block diagram of the electronics is shown in Figure 6. Beam synchronized timing is brought in on a fiber-optic link. Division of the difference by the sum is done in the high level application code.

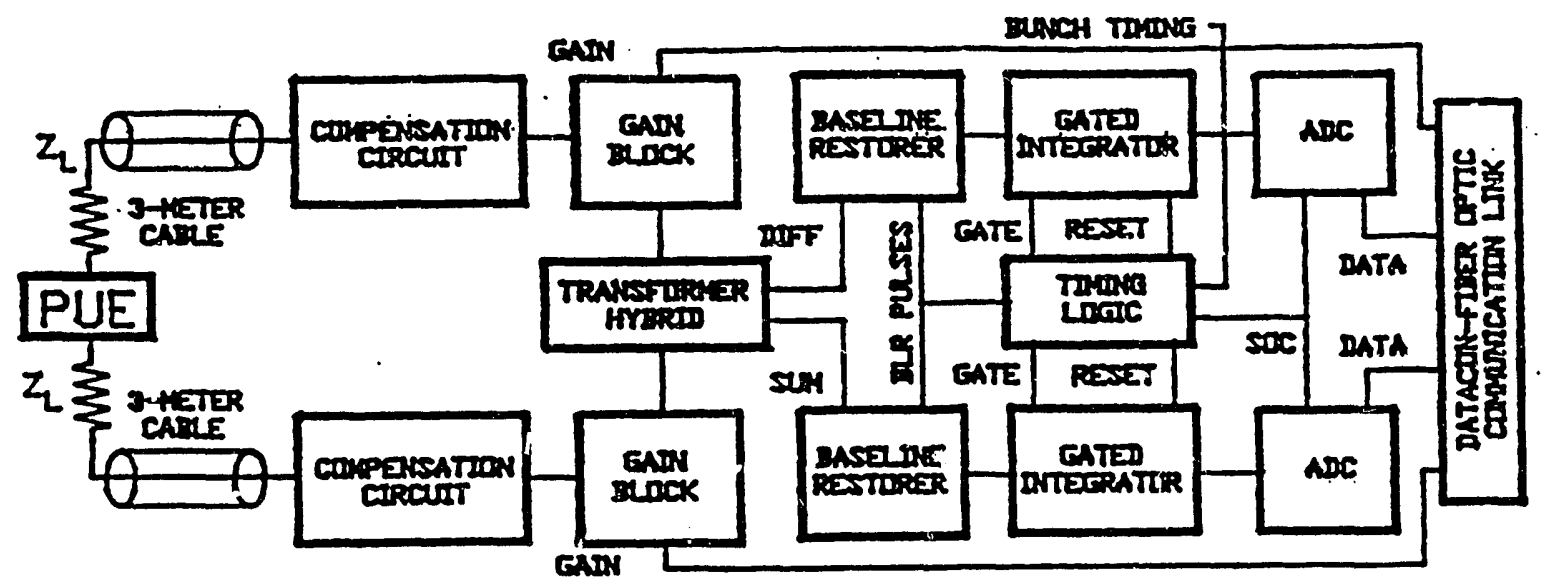

Fig. 6. Block diagram of PUE local electronics. 
The Front End Board (FEB) provides gain and takes the sum and difference of the bunch signals. The compensation Circuit provides a match at high frequency but high impedance at low frequency, flattening the response to $\pm 1.5 \mathrm{~dB}$ from $10 \mathrm{kHz}$ to $30 \mathrm{MHz}$. An AD9610 low noise amplifier provides gains of $0.1,1$ and $10 . A$-port trifilar transmission line transformer with more than 60 dB common mode performs the sum and difference. Overall, the FEB provides a difference signal of $-50 \mathrm{~dB}$ with respect to the sum from $50 \mathrm{kHz}$ to $20 \mathrm{MHz}$, with most reaching $-55 \mathrm{~dB}$. Either the amplified single plate or sum and difference bunch signals can be sent on analog fiber optic links 15 from the Booster tunnel. These analog links have a bandwidth of $6 \mathrm{~Hz}$ to $35 \mathrm{MHz}$ and linearity better than $3 \%$ over a 26 dB dynamic range.

The Acquisition Board performs the baseline restoration, integration and digitization of the bunch data. The BLR sets the zero of the AC-coupled signals by using a balanced diode bridge (HP 5082-2813) to ground the line between bunches. The Gated Integrator accepts the desired number of bunches $(1-240)$, integrating and holding the data until read $(50 \mu \mathrm{sec})$ by an on-board 16-bit ADC. The digital data goes directly to the controls interface in each crate.

The 60 nsec BLR pulses must fall between bunches within a 20 nsec error over the RF rarige. The equally spaced PUEs require BLR pulses at (48/harmonic) phases, which must ripple around the Ring to measure the single turn trajectory. BLR triggers and integrator gate are generated by the Bunch Timing sequencer. The Low Level RF (LLRF) system generates a signal, phase-locked to the beam, at 48 times the revolution frequency using a direct digital synthesizer (stanford Telecommunications Inc. santa Clara CA, Model STEL 9273). These pulses clock a 48-bit ECL shift register to make the evenly phased triggers. The gate time is encoded by counting the RF frequency for the desized number of bunches, starting at the desired time. These are the data clocked through the shift register. This allows each PUE to get all its timing information on a single fiber optic link, avoiding high power line-compensated drivers while providing ground isolation.

Hewlett-packard HFBE-1404 GaAlAs transmitters drove the signals down $200 \mathrm{~m}$ of $200 \mu \mathrm{m}$ Ensign Bickford HCR step index silica cable to HFBR-2404 GaAlAs photo-diode receivers. Tests in the AGS ${ }^{16}$ showed $<2$ dB loss for the receiver and $<1 \mathrm{~dB}$ loss for the transmitter for 28 kRad(Si). Attenuation for cables exposed to this flux was under $0.1 \mathrm{~dB} /$ meter. 
All of the electronics crates were installed in the tunnel for commissioning, but only 34 of 46 were able to provide data through the computer. Phase locking the Timing sequencer to the beam through the LLRF was more difficult than expected and in the beam studies time available, was achieved only for a single frequency. A beam bunch simulator has since been built and is now being used to synchronized the sequencer over the full frequency range. Another problem first observed during commissioning was noise from the BLR pulses coupling to the FEB, which, at the low intensity $\left(2 \times 10^{10}\right)$ used for most of the studies, made the orbit data meaningless. As the intensity was raised, the sum signal began to behave reasonably but no orbit could be seen until the intensity was over 1011. Following the beam runs the major source of the noise was found and steps are being taken to eliminate it. The amplified bunch signals sent on the analog fiber oftic lines were quite clean even at 2 $x 10^{10}$ (if the BLR pulses were turned off) and were heavily used during the commissioning. Figure 7 shows a typical signal with some BLR noise.

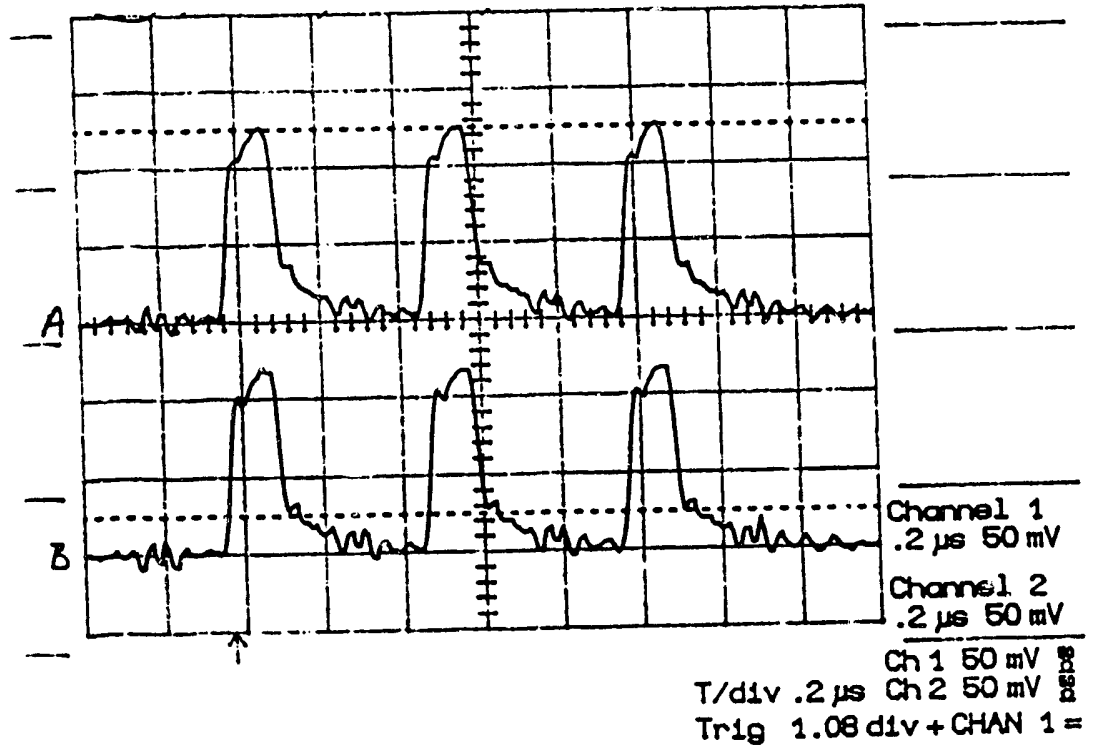

Fig. 7. Bunch signals from "A" and "B" plates of horizontal PUE at $\mathrm{CE}$ ( $\mathrm{H}^{-}$injection). single turn injected ( 3 bunches). Total charge $=2 \times 10^{10}$.

\section{The Ring Profile Monitor}

Flying wires were rejected as the Booster profile monitor because partially stripped heavy ions would be further stripped and lost. A residual gas ionization profile monitor (IPM) would work with heavy ions but even with enhancement by micro channel plates (MCPs) 
there are too few interactions in 1 msec by $2 \times 1010$ polarized protons at $3 \times 10^{-11}$ Torr to be meaningful. 17 Since the Booster will accumulate 20 such pulses it would be useful through most of the cycle. An IPM has been built for the Booster. is

IPMs which used MCPs did not have to operate at the high vacuum or over the intersity range of the Booster. Kriderl9 used a 2 layer MCP with a 1 msec integration

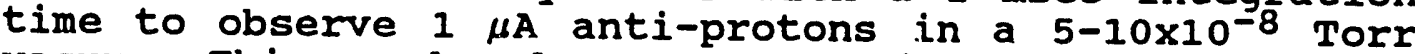
vacuum. This produced a number of ions similar to that of the accumulated polarized beam. MCP degradation with increasing charge output was observed by Krider and by Kawakubo, et al.20 In the AGS Booster an UV light will be used to track the calibration of the MCPs. To extent the life of the MCPs the controls adjust the bias voltage to limit anode current. The bias voltage will be rapidly gated on only during measurements.

Because of the high vacuum, the resistive divider normally used to produce a uniform electric field was unsuitable so specially contoured stainless steel electrodes were designed.2I A POISSON equipotential plot is shown in Figure 8. A third set of electrodes mounted at

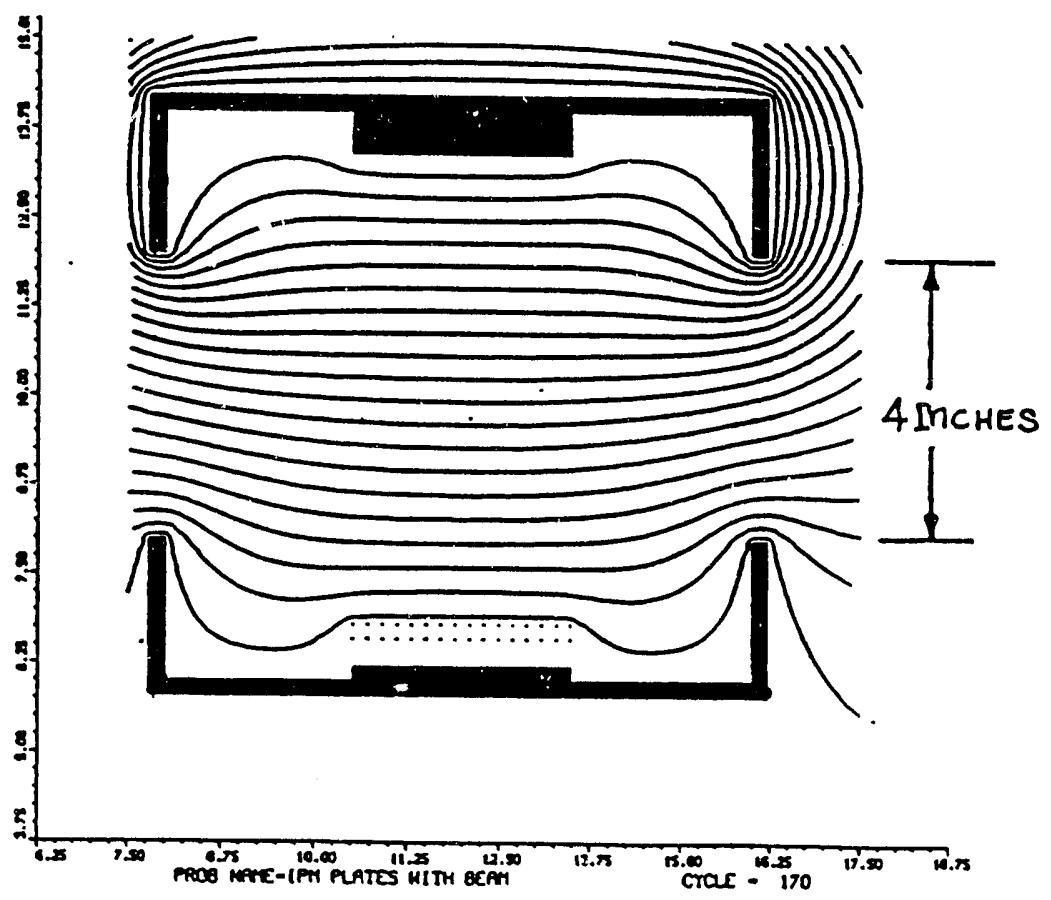

Fig. 8. POISSON plot of IFM equipotentials. 
$45^{\circ}$, is used to compensate the effect of the other two on the beam. The electrodes are 2 inches deep and 8 inches square with a 4 inch gap. The MCP array sits in an opening in the grounded electrode. Each detector plane consists of a 2 layer MCP capable of $10^{7}$ gain. with an integral 64 channel anode array. The collectors are $1.1 \mathrm{~min}$ wide on a $1.47 \mathrm{~mm}$ pitch, $75 \mathrm{~mm}$ long. 22 Further details of the IPM are presented in another paper at this conference. 23 Everything but the detector was vacuum fired to $950^{\circ} \mathrm{C}$. The entire IPM was baked to $300^{\circ} \mathrm{C}$.

The VME-based electronics for the IPM scans both 64 channel planes into memory in less than $1 \mathrm{msec}$. Each anode is connected to a low leakage (< $10 \mathrm{pA})$ gated integrator 4 followed by a sample and Hold (Datel DVME-645) allowing the integrator to be reset and started again while the data is being processed. A microprocessor controlled 12-bit ADC VME board (Datel DVME-601) digitizes the voltages and puts the data into dual port memory at a $140 \mathrm{kH}$. rate. A bus translator (Bit-3 Corp.) maps the dual port KAM into the address space of the remotely located control computer. During commissioning the IPM was controlled by a "286 AT-Clone" but it will be connected to the AGS Apollo based control system.

The IPM MCP bias was on for about 30 minutes during Booster commissioning, during which beam profiles were obtained. Beam time was much less since the duty factor was under 10\%. No obvious degradation was observed although the plates have not been re-calibrated. Figure 9 shows the raw data for a pair of profiles taken 64.5 msec into the injection flat-top. The proton intensity was $8 \times 10^{10}$ at a vacuum of $2 \times 10^{-10}$ Torr, 4 times the minimum intensity and over 6 times the minimum pressure to be expected. The signals are very clean except for some repeatable noise following the horizontal profile, which could have been subtracted from the baseline. The peak counts were somewhat over half scale but the MCP could have provided another 50-100 times more signal. Up to 16 scans were made per Booster cycle. While there were no failures during commissioning, the IPM was not completely operational, using temporary timing and roughly calibrated voltage readbacks. Being off the main control network prevented access to the database so there was no on-line momentum, vacuum or intensity information. Testing time was limited because the bias voltage pulser was not installed. 

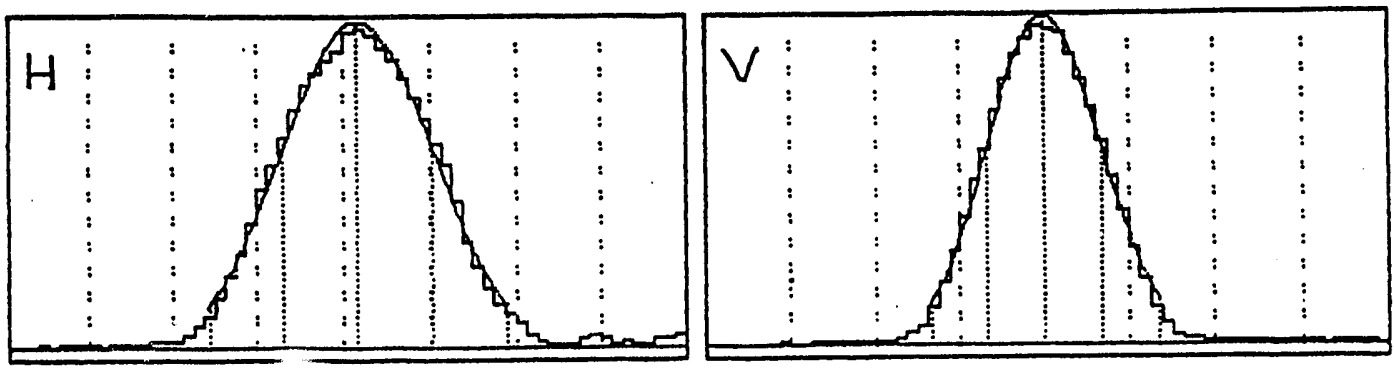

Fig. 9. IPM generated profiles for $8 \times 10^{10}$ protons, at $2 \dot{u} \mathrm{MeV}, 2 \times 10^{-10}$ Torr, 1 msec integration. Max. horizontal signal $=5.02 \mathrm{~V}, \max$. vertical signal $=$ $6.39 \mathrm{~V}$.

\section{Acknow ledgments}

While the entire AGS Instrumentation Group contributed to the construction of the Booster, certain individuals were responsible for the specific work reported here. R. Witkover, E. Zitvogel and $S$. Naase worked on the Ring beam current transformers, The LTB BPMs were designed by $R$. Bossart of CERN and J. Brodowski of BNL. The circuits were by T. Shea, V. LoDestro and C. Degen. The Ring PUE was designed by $w$. Van $Z$ wienen, and tested by R. Thomas. The PUE electronics were designed by $D$. Ciardullo and G. Smith of BNL with help from E. Schulte of CERN. E. Beadle did the fiber optic work. A. Stillman was responsible for the IPM, with R. Thern working on the AT computer interface.

\section{DISCLAIMEK}

This report was prepared as an account of work sponsored by an agency of the United States Government. Neither the United States Government nor any agency thereof, nor any of their employees, makes any warranty, express or implied, or assumes any legal liability or responsibility for the accuracy, completeness, or usefulness of any information, apparatus, product, or process disclosed, or represents that its use would not infringe privately owned rights. Reference herein to any specific commercial product, process, or service by trade name, trademark, manufacturer, or otherwise does not necessarily constitute or imply its endorsement, recommendation, or favoring by the United States Government or any agency thereof. The views and opinions of authors expressed herein do not necessarily state or reflect those of the United States Government or any agency thereof. 


\section{REFERENCES}

E. R. Beadle and G. w. Bennett, "The AGS Booster Radiation Loss Monitor system", Proceedings of the Second Annual Workshop on Accelerator Instrumentation, Batavia, IL, p 35-47. AIP Conf. Proc. 229, American Institute of Physics, NY, 1990, p 35-47.

A. N. Stillman, R. E. Thern, R. L. Witkover and W.H. Van Zwienen, "Design of the AGS Booster Ionization profile Monitor", Proceedings of the 1991 Particle Accel. Conf., San Fransisco, CA.

Model DL-150BR/DG-01.5BR, Manufactured by both: NTG, Im Steinigen-Graben 12-14, D-6460 Gelnhausen-Hailer, W. Germany and PET Ing.-Buro, D-6100 Darmstadt, W. Germany

T. J. Shea, C. M. Degen, D. M. Gassner and V. LoDestro, "A Beam Position Monitoring System for Brookhaven's Linac to Booster line", Proceedings of the second Annual Workshop on Accelerator Instrumentation, Batavia, IL, 1990, p. 273-9, AIP Conf. Proc. 229, Amerizan Institute of Physics, NY, NY, 1991.

R. L. Witkover, et al., "Beam Instrumentation for the BNL Heavy Ion Transfer Line", IEEE Cat. No. 87CH2387-9, Wash., DC, 567 (1987).

A. Stevens, private communication.

7 Manufactured by Ion Physics Corporation, 323 Andover street, Wilmington, MA, 01887.

8 K. B. Unser, "A Toroidal DC Current Transformer with High Resolution", IEEE Trans. Nucl. Sci., NS-28, No. 3, 2344 (1981).

9 Manufactured by BERGOZ, crozet, 01170 GEX, France.

10 R. Bossart, "Resonant Beam Position Monitor for Low Beam Intensity", CERN SPS/88-4 (ABM), December 1987.

11 S. P. Jachim, R. C. Webber, R. E. Shafer, "RF Beam Position Measurement Module for the Fermilab Energy Doubler", IEEE Trans. Nucl. Sci., NS-28, No. 3, 2323 (1981).

12 F. D. Wells and S. J. Jachim, "A Technique for Improving the Accuracy and Dynamic Range of Beam Position Detection Equipment", IEEE Cat. No. 89CH2669-0, Chicago, IL, 1595 (1989).

13 D. J. Ciardullo et al, "The AGS Booster Beam Position Monitor System", Proceedings 1991 Particle Accel. 
Conf., San Fransisco, CA., to be published.

14 R. Thomas, et al., "Design and Tesing of the AGS Booster BPM Detector", Proceedings of the 1991 Particle Accel. Conf., San Fransisco, CA, to be published.

15 Meret Inc., 3.81524 th Street, Santa Monica, CA, 90404. Model No. MDi2 288TV.

16 E. Beadle, private communication.

17 R. L. Witkover, private communication.

18 A. N. Stillman, R. E. Thern, R. L. Witkover and W. H. Van zwienen, "Design of the AGS Booster Ionization profile Monitor", Proc. 1991 Part. Accel. Conf., San Fransisco, CA, to be published.

19 J. Krider, "Residual Gas Beam Profile Monitor", Nucl. Instrum. Meth., $\underline{\text { A278 }}$ (3), 660 (1989).

20 T. Kawakubo, T. Ishida, E. Kadokuro, Y. Ajima, T. Adachi. "Fast Data Acquisition System of a Non-Destructive profile Monitor for a synchrotron Beam by Using Micro Channel Plate with Multi-Anodes", to be published in Nucl. Instrum. Meth.

21 E. Leal-Quiros and M. A. Prelas, "New Tilted Poles Wein Filter with Enhanced Performance", Rev. Sci. Instrum., 60, No. 3, 350 (1989).

22 Galileo Mosel 3810 with 64 element anode. Manufactured by Galileo Electro-optics Corp., Galileo Park, PO Box. 550, Sturbridge, MA 01566.

23 A. N. Stillman, R. E. Thern, R. L. Witkover and W. H. Van Zwienen, "Design and Operation of the AGS Booster Ionization Profile Monitor", these proceedings.

24 Manufactured by Advanced Technology Laboratories, Inc., 1111 Street Road, Southampton, PA 18966. 

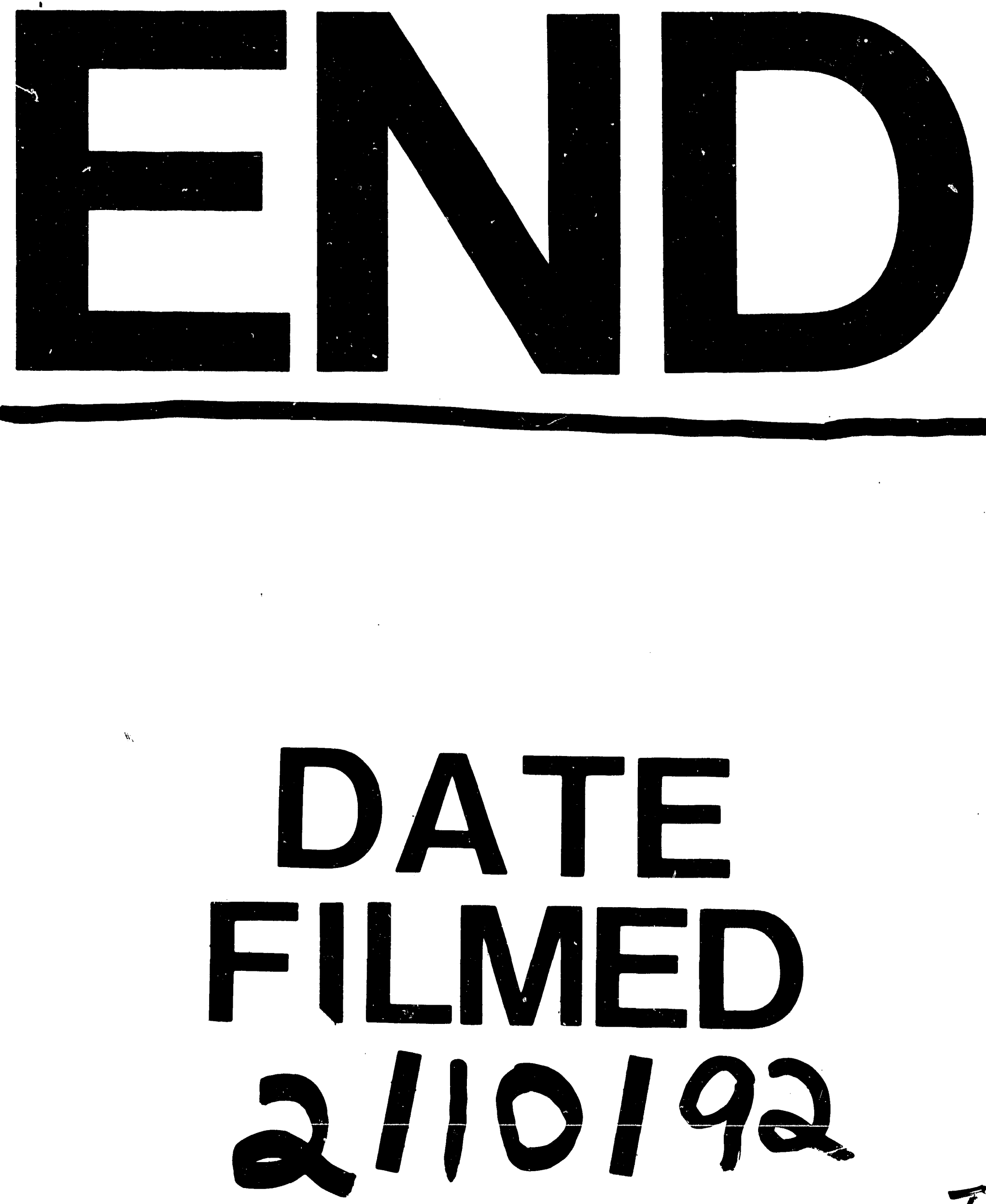

$I$ 
